\title{
La « Barbarisation » d'Éphèse vue à travers le prisme de l'anthroponymie
}

Par

\section{Fabrice Bouzid-Adler}

Doctorant à l'Université de Strasbourg

ous la domination achéménide, Éphèse tint une place
particulière parmi les cités grecques d'Ionie. En effet, la
cité et son célèbre sanctuaire d'Artémis, déjà honoré et
specté par les anciens rois lydiens, profita de la bienveillance des
uverains achéménides et de leurs satrapes. A l'issue des guerres
édiques, Xerxès épargna ainsi l'Artémision tandis qu'il ravageait
Didymeion de Milet ${ }^{1}$. Plus tard, à la fin du $V^{\mathrm{e}}$ siècle av. J.-C.,
aire. Nous savons par Thucydide que, pendant l'hiver $411-410$,
séjourna à Éphèse et y fit un sacrifice à Artémis ${ }^{2}$. Peu après, la

${ }^{1}$ StRABOn, Géographie, XIV, 1, 5.

${ }^{2}$ ThUCYDide, La guerre du Péloponnèse, VIII, 109, 1. 
satrape rassembla une armée pour aller «au secours d'Artémis $»^{3}$. Outre cet intérêt porté à un sanctuaire majeur de l'Asie mineure occidentale, les auteurs anciens font état d'une réelle iranisation de la cité. Le témoignage le plus clair sur cette proximité entre Grecs et Perses à Éphèse est celui de Plutarque qui dénonça dans un passage de sa Vie de Lysandre ce qu'il considérait comme une «barbarisation » de la cité :

Arrivé à Éphèse, Lysandre trouva la ville bien disposée pour lui et très zélée pour la cause de Sparte ; mais elle était alors dans un triste état et en danger de se barbariser et de se laisser influencer par les mœurs perses, car elle était entourée par la Lydie et les généraux du roi y séjournaient la plupart du temps.4

Cet épisode se situe vers 407-405 et constitue, dans le récit de Plutarque, comme l'introduction d'une critique sur la complaisance de Lysandre vis-à-vis du prince Cyrus le Jeune. En effet, l'auteur accuse le navarque de s'être montré courtisan pour obtenir les subsides perses et il lui oppose la figure de Callicratidas, rude Dorien qui répugna à mendier aux portes de Sardes ${ }^{5}$. D'une certaine manière, le triste état de la ville préfigurait l'abaissement moral de Lysandre. On retrouve ici le thème, cher à Plutarque, selon lequel la proximité avec les Asiatiques présente une menace pour l'hellénisme en encourageant l'amollissement de la cité. Ce thème se retrouve notamment à propos du roi Léonidas II de Sparte $^{6}$. Les modalités de cette iranisation d'Éphèse sont assez mal connues. Pour cette raison, un passage de Démocrite, cité par Athénée, est du plus grand intérêt. L'auteur, justement originaire d'Éphèse, traite de l'adoption par ses concitoyens de riches vêtements iraniens : il décrit notamment les aktaiai, particulièrement onéreuses, tissées dans une seule pièce de tissu et parsemées de perles d'or ${ }^{7}$. Une fois encore, le propos est polémique puisqu'il s'agit de critiquer le goût des Ephésiens pour le luxe asiatique.

Comme nous venons de le voir, cette «barbarisation» de la cité d'Artémis serait imputable à la proximité entre les Grecs et les Iraniens vivant en Lydie ou séjournant en ville. Au delà de la venue ponctuelle de satrapes de Sardes, comme Tissapherne, la présence iranienne a sans doute été constante pour permettre ces échanges culturels si décriés par les Anciens. On peut notamment penser à une présence militaire chargée de conserver la cité dans la domination royale. Arrien atteste ainsi que lors de la conquête macédonienne, une garnison achéménide occupait Éphèse ${ }^{8}$. Natu-

\footnotetext{
3 XÉnOPHOn, Helléniques, I, 2, 6-10.

4 Plutarque, Lysandre, III, 3 (traduction A.-M. OZANAm, 2001).

${ }^{5}$ PlutARQue, Lysandre, VI-VII.

${ }^{6}$ Plutarque, Agis, III, 9.

7 ATHÉNÉE, Les Deipnosophistes, XII, 19525 c-e.

8 ARrien, Anabase, I, 17, 9.
} 
rellement, cette présence militaire dut varier en fonction des aléas politiques. L'épigraphie suggère cependant qu'elle laissa des traces dans la toponymie de la ville. Ainsi, une inscription éphèsienne du début du III ${ }^{\mathrm{e}}$ siècle avant J.-C. évoque une colline d'Astyage (ó

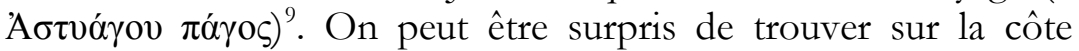
égéenne un toponyme construit sur le nom du dernier Grand Roi mède (détrôné par Cyrus le Grand vers 550 av. J.-C.). A moins de supposer que ce nom a été donné sous la domination lydienne pour honorer le beau-frère de Crésus ${ }^{10}$, il semble préférable de supposer qu'il a été donné à la colline à l'époque achéménide. L'inscription mentionne une tour construite à son sommet. Dès lors, il est fort probable que ce lieu a servi comme poste de guet dans cette région si disputée entre Grecs et Perses. Le nom Astyage vient peut-être d'un phrourarque iranien, d'origine mède, qui aurait tenu un temps ce poste.

Toute la question est de savoir si Éphèse connut ou non une implantation durable d'Iraniens dans le cadre de la diaspora impériale achéménide. L'anthroponymie est un outil intéressant pour essayer de le déterminer. En effet, les fouilles commencées dans la seconde moitié du XIX ${ }^{\mathrm{e}}$ siècle ont permis de mettre au jour de nombreuses inscriptions dont un grand nombre mentionne des noms d'origine iranienne. Le principal problème est, comme nous allons le voir, d'interpréter cette anthroponymie iranienne qui, pour son immense majorité, est postérieure à l'époque achéménide.

\section{Attestations aux époques achéménides et hellénis- tiques}

A. Le Mégabyze d’Éphèse

Les auteurs anciens ${ }^{11}$ nous font connaitre des prêtres néocores d'Artémis d'Éphèse qui portèrent le titre sacerdotal de Mégabyze

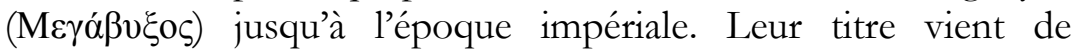
l'anthroponyme vieux-perse Baga-bux̌̌a signifiant «Qui est au service du dieu $»^{12}$. Il est fort probable que des Iraniens aient assuré ce sacerdoce à l'époque achéménide et que leur nom se soit perpétué après la chute de l'empire en devenant un titre. Strabon écrit qu'il s'agissait d'eunuques venus de pays lointains à la de-

\footnotetext{
${ }^{9}$ R. MerkelBach - J. Nolle, Die Inschriften von Ephesos VI, Bonn, 1980, $\mathrm{n}^{\circ} 2052,1.7$ et 9 .

${ }^{10}$ En effet, HÉrodote, Histoires, I, 74 mentionne le mariage entre Astyage fils de Cyaxare, prince héritier mède, et Aryènis fille d'Alyatte et donc sœur de Crésus.
}

11 Xénophon, Anabase, V, 3, 6-7 ; Appien, Les guerres civiles, V, 1, 9 ; Pline, Histoire Naturelle, XXXV, 36, 7 et 40, 7 ; TZETZES, Chiliades, VIII, 198 ; ELIEN, Histoire variée, II, 2.

12 E. BENVENisTe, Titres et noms propres en iranien ancien, Paris, 1966, p.109113. 
mande des Ephésiens pour les besoins du culte ${ }^{13}$. Quoi qu'il en soit, le fait qu'un nom personnel soit devenu un titre cultuel témoigne de l'influence iranienne sur le culte d'Artémis. Deux inscriptions de Priène évoquent le Mégabyze qui exerçait sa charge à l'époque de la chute de l'empire achéménide.

\section{Décret honorifique de Priène}

Inscription trouvée à Priène. Datation : fin du $\mathrm{IV}^{\mathrm{e}}$ siècle (330300 av. J.-C.).

Éditions et commentaires : W. DITTENBERGER, Sylloge inscriptionum Graecarum, Leipzig, 1883 (3e éd.), nº 282 II ; F. H. v. GAERTRINGEN, Inschriften von Priene, Berlin, 1906, n³ ; J. WACKERNAGEL, "Onomatologica » Hermes 58 (1923), p. 462-464 ; D. MCCABE - R.N. ElliotT - A. Hilton - C. REDMOnD, Priene Inscriptions. Texts and list, Princeton, 1991, nº3 ; W. BLÜMEL - R. MerkelBACH, Die Inschriften von Priene, Bonn, 2014, nº16.

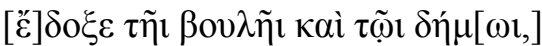

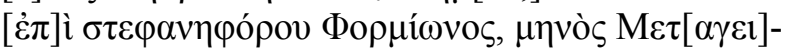

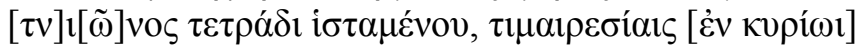

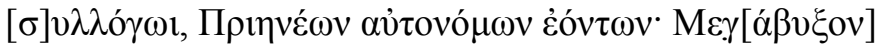

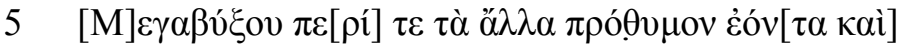

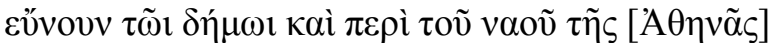

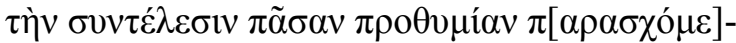

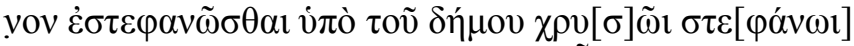

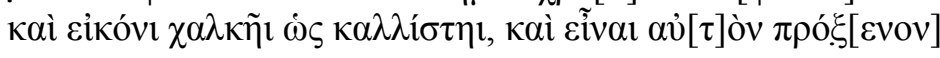

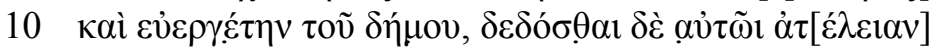

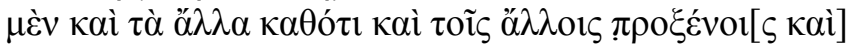

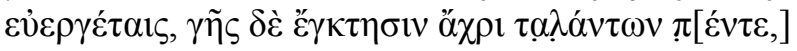

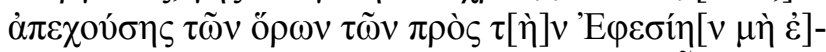

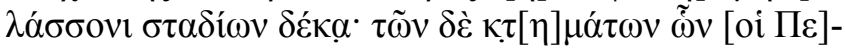

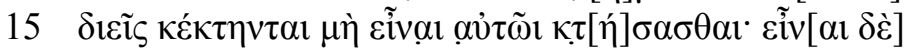

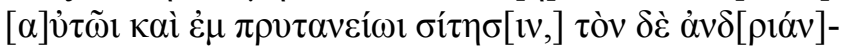

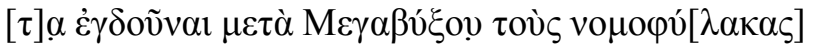

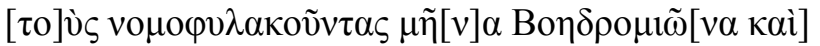

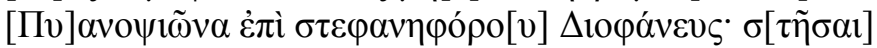

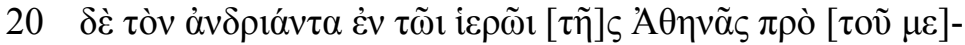

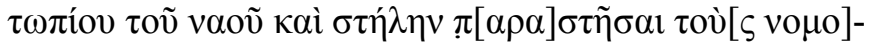

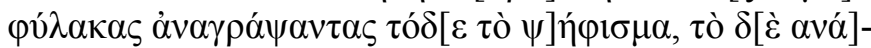

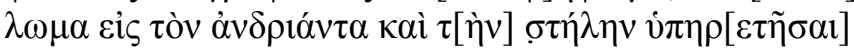

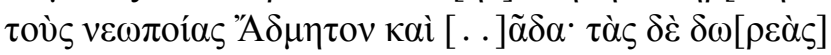

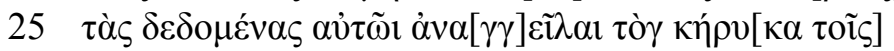

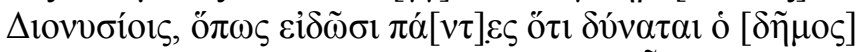

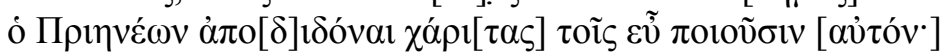

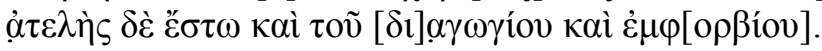

Il a plu au conseil et au peuple, sous l'archontat de Phormiôn, le $4^{\mathrm{e}}$ jour du présent mois de Métageitniôn, lors d'élections de magistrats dans une assemblée souveraine, Priène étant indépendante, que Mégabyze successeur de Mégabyze, étant à tous égards plein de bonne volonté et de bienveillance envers le peuple et

13 Strabon, Géographie, XIV, 1, 23. 
ayant fait preuve de tout l'empressement possible pour l'achèvement du temple d'Athéna, soit honoré par le peuple d'une couronne d'or et d'une statue de bronze la plus belle possible ; qu'il soit proxène et évergète du peuple ; que lui soient accordés l'exemption de taxes et tous les autres privilèges qui sont accordés aux autres proxènes et évergètes, l'acquisition d'une terre d'une valeur de cinq talents maximum, éloignée des frontières regardant vers Éphèse de pas moins de dix stades, qu'il ne lui soit pas permis d'acquérir les propriétés que les Pédieis_ont acquises. Qu'il lui soit accordée aussi la nourriture au prytanée et que les nomophylaques qui sont en fonction les mois de Boédromiôn et de Pyanopsiôn sous l'archontat de Diophanès remettent avec Mégabyze la statue; que les nomophylaques la dressent dans le sanctuaire d'Athéna devant la façade du temple et qu'ils placent à côté une stèle après avoir fait graver ce décret ; que les néopes Admétos et (...) participent à la dépense pour la statue et la stèle ; que le héraut annonce aux Dionysia les honneurs qui lui ont été décernés afin que tous sachent que le peuple de Priène peut attribuer des faveurs à ceux qui lui rendent service. Qu'il soit exonéré d'impôts et des taxes de transit et de pâture.

Cette inscription est fort intéressante car elle nous permet de mieux connaitre l'action d'un individu mentionné dans les sources littéraires. En effet, ce Mégabyze est celui qui vit la chute de l'empire achéménide. C'est donc sans doute lui qui se fit le porteparole des Ephésiens pour décliner l'aide d'Alexandre qui voulait reconstruire l'Artémision incendié. Preuve de la considération dont il jouissait, le néocore entretint, aux dires de Plutarque, une relation épistolaire avec le roi macédonien ${ }^{14}$. Enfin, ce même Mégabyze semble avoir été féru de peinture grecque car nous savons qu'il fit décorer son tombeau par Nicias d'Athènes et qu'Apelles, le portraitiste d'Alexandre réalisa un tableau le représentant lors de la procession de l'exodos ${ }^{15}$. Le décret de Priène nous permet d'apprendre qu'en plus des activités inhérentes à sa charge à Éphèse même, ce Mégabyze joua un rôle non négligeable dans d'autres cités ioniennes comme ici, à Priène, où il favorisa la construction du temple d'Athéna Polias. Le texte suggère que son action ne fut pas ponctuelle et qu'elle s'inscrivit dans de bonnes relations entre lui et cette cité. Pour prix de leur gratitude, les Priéniens l'honorèrent d'une couronne d'or, d'une statue et de repas au prytanée. Ils le firent également proxène et évergète avec les privilèges liés à ces fonctions. Enfin, il se vit octroyer des privilèges fiscaux et, surtout, l'enktésis gès lui permettant d'acquérir des terres sur le territoire civique (à quelques restrictions près). Sans aller jusqu'à lui décerner la citoyenneté priènienne, ce décret était donc des plus intéressants pour le Mégabyze lequel voyait son prestige régional accru.

\footnotetext{
14 Plutarque, Alexandre, XLII, 1.

15 PLINE, Histoire naturelle, XXXV, 36, 30 et 40, 7.
} 
Un point de la traduction mérite d'être éclairci. Le néocore est

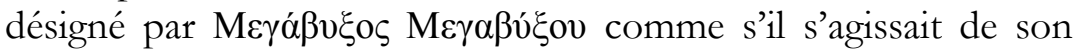
nom personnel suivi de son patronyme. La traduction serait donc, en théorie, "Mégabyze (fils) de Mégabyze ». Si tel était le cas, cela laisserait sous-entendre que cette prêtrise était détenue par une dynastie sacerdotale comparable à celle des Branchides à Milet. Cependant, Strabon assure que la particularité de cette fonction était d'être détenue par des eunuques. W. Blümel et $\mathrm{R}$. Merkelbach ont proposé comme compromis qu'il s'agisse d'un fils adoptif ${ }^{16}$. Cependant, par prudence, nous avons opté pour la formule « (successeur) de Mégabyze». Il est clair cependant que la formule employée est ambiguë sur la nature, anthroponyme ou titre, de ce terme étranger.

\section{Dédicace de la statue}

Inscription gravée sur la base de la statue évoquée dans l'inscription précédente. Datation : fin du IV siècle (330-300 av. J.-C.).

Éditions et commentaires : F. H. v. GAERTRINGEN, Inschriften von Priene, Berlin, 1906, n²31; J. WACKERNAGEL, « Onomatologica » Hermes 58 (1923), p. $462-464$; D. MCCABE - R.N. ElliotT - A. Hilton - C. ReDmond, Priene Inscriptions. Texts and list, Princeton, 1991, $\mathrm{n}^{\circ} 248$; W. BLÜMEL - R. MERKELBACH, Die Inschriften von Priene, Bonn, 2014, nº150.

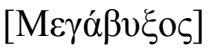

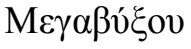

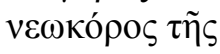

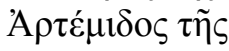 \\ $5 \quad \dot{\varepsilon} v^{\prime} E \varphi \varepsilon ́ \sigma \omega t$.}

Mégabyze successeur de Mégabyze, néocore d'Artémis, celle d'Éphèse.

Cette courte dédicace fut gravée sur la base de la statue du Mégabyze d'Éphèse élevée pour le remercier de son action dans la construction du temple d'Athéna Polias à Priène. Le monument fut d'ailleurs érigé dans l'enceinte du sanctuaire, devant la demeure de la déesse. La statue, réalisée en bronze, n'a malheureusement pas été conservée. Que représentait-elle ? Selon W. Blümel et R. Merkelbach, il pourrait s'agir soit de la déesse Athéna, soit de Mégabyze lui-même ${ }^{17}$. La seconde hypothèse semble assez vraisemblable. On peut toutefois supposer, avec L. Robert $^{18}$, qu'elle figurait le Mégabyze revêtu de ses habits sacerdotaux. Une statuette en ivoire, que l'on suppose être celle d'un néocore d'Artémis de l'époque mermnade, montre un homme 61.

16 W. BlüMel - R. MerkelBaCH, Die Inschriften von Priene, Bonn, 2014, p.

17 W. BlÜMEL - R. MerkelBaCH, Die Inschriften von Priene, Bonn, 2014, p. 370.

${ }^{18}$ L. RoBerT, Hellenica XI-XII, Paris, 1960, p. 458-459. 
imberbe coiffé d'un calathos et revêtu d'une riche robe ornée de svastikas $^{19}$. Il porte autour du cou une chaîne qui est peut-être un des emblèmes de sa charge. Ce costume, qui a peut-être évolué au cours des siècles, n'est pas sans faire penser à celui de Battakès, prêtre de Cybèle, qui vint à Rome en 103 av. J.-C. Selon Diodore, celui-ci portait une couronne d'or et une robe brodée d'or ${ }^{20}$. Ces parallèles peuvent permettre de se faire une idée de ce à quoi a pu ressembler la statue du Mégabyze à Priène.

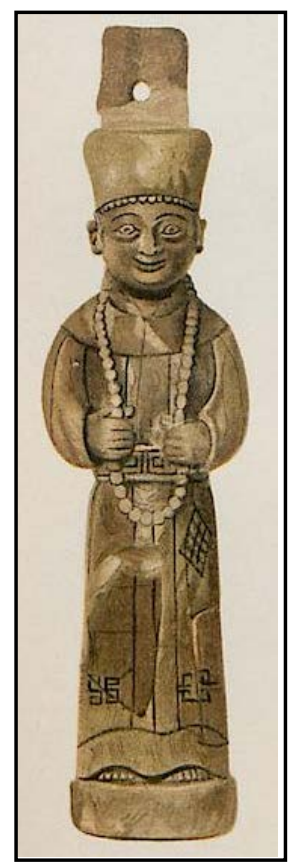

Ivoire découvert à Éphèse ${ }^{21}$

\section{B. Mithrès fils d'Astéas}

Décret civique gravé sur un pilier rectangulaire en marbre blanc découvert à Éphèse par J. Keil et G. Maresch dans les thermes de Scholasticia. Ce texte ne concerne notre sujet qu'en raison du nom de celui qui a fait la proposition du décret c'est pourquoi nous ne le reproduisons que partiellement. 87,5 x 71, 5 x $59 \mathrm{~cm}$. Datation : époque hellénistique (II siècle av. J.-C.).

Éditions et commentaires : J. ROLLEY - G. MARESCH, « Epigraphische Nachlese zu Miltners Ausgrabungsberichten aus Ephesos » Jahreshefte des Österreichischen Archäologischen Instituts in Wien 45 (1960), n¹3 ; L. ROBERT, "Sur des inscriptions d'Ephèse : fêtes, empereurs, épigrammes " Revue de Philologie 41/1 (= Opera Minora Selecta 5, 1989), p. 7-32 ; Bulletin Épigraphique, 1967, n496 ; H. WANKEL, Die Inschriften von Ephesos I, Bonn, 1979, n6 (Pl.7).

${ }_{19} \mathrm{Cl}$. Rolley, La sculpture grecque I, des origines au milieu du $V^{e}$ siècle, Paris, 1994, p. 260-261

${ }^{20}$ DIODORE, Bibliothèque historique, XXXVI, 14.

${ }^{21}$ D. G. HogarTh, Excavations at Ephesus, The archaic Artemisia, London, 1908, Pl. XXI, 2. 


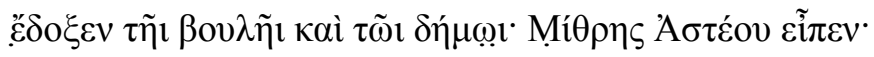

(suit le décret honorant Diodoros)

Il a plu au conseil et au peuple, sur proposition de Mithrès fils d'Astéas,

(suit le reste du décret honorant Diodoros)

Ce texte est un décret honorifique de la cité d'Éphèse pour le gymnasiarque Diodoros. Il a été émis sur la proposition d'un certain Mithrès, fils d'Astéas. Ce nom mithriaque est assez courant en Asie mineure occidentale. Suggère t-il ici une origine iranienne pour celui qui le porte? Rien ne permet d'en être assuré.

\section{Attestations à l'époque romaine}

\section{A. Mazaios et Mithridatès}

Plusieurs documents d’Éphèse concernent les dénommés Mazaios et Mithridatès. Affranchis respectivement par Auguste et par Agrippa, ils possédaient une fortune très importante et firent partie de l'élite municipale. Leur principale réalisation fut la construction de la porte de l'agora commerciale dédiée à leurs protecteurs. Leur origine n'est, à ma connaissance, pas connue.

\section{La Porte de Mazaios et Mithridatès}

Située à côté de la célèbre bibliothèque de Celsus, la porte de marbre construite par Mazaios et Mithridatès monumentalise l'entrée sur l'agora commerciale de la ville. Sa façade sud porte deux inscriptions : l'une en langue grecque au-dessus de l'arche centrale et l'autre, en langue latine, au-dessus des trois arches. Les restes de petites chevilles indiquent que les lettres étaient rendues plus visibles par l'usage de bronze. Datation : 4-3 av. J.-C.

Éditions et commentaires : H. Dessau, Inscriptiones Latinae Selectae, Berlin, 1892-1916, n8897 ; Année Épigraphique, 1903, nº98 ; J. KEIL, Forschungen in Ephesos III, Wien, 1923, n6, p.52-53 et 58 (figs. 85-86 et 96) ; Année Épigraphique 1924, $\mathrm{n}^{\circ} 68$; V. EHRENBERG - A. H. M. JONES, Documents illustrating the reigns of Augustus and Tiberius, Oxford, 1976, nº71 ; R. MERIÇ - R. MERKELBACH - J. NOLLE - S. ŞAHIN, Die Inschriften von Ephesos VII, 1, Bonn, 1981, n³006 ; D. MCCABE - R.N. ElliotT - A. Hilton - C. Redmond, Ephesos Inscriptions. Texts and list, Princeton, 1991, $\mathrm{n}^{\circ} 258$; H. THÜR, ,....und verschönerte die Stadt..." Ein ephesischer Priester des Kaiserkultes in seinem Umfeld, Wien, 1997, p.69-75 ; R. A. KEARSLEY - T. V. Evans, 2001, Greeks and Romans in Imperial Asia. Mixed Language Inscriptions and Linguistic Evidence for Cultural Interaction until the End of AD III (Inschriften griechischer Städte aus Kleinasien 59), Bonn, 2001, n¹51 ; Supplementum Epigraphicum Graecum XLVII, n 1617.

\footnotetext{
(Partie centrale) Mazaeus et Mithridatès patronis

(Partie Gauche) Imp. Caesari Divi f. Augusto pontifici maximo, cos. XII, tribunic. potest. XX et Liviae Caesaris Augusti
}

(Partie Droite) M. Agrippae L. f. cos. tert. imp. tribunic. 
potest. VI et

Iuliae Caesaris Augusti fil.

(partie centrale). Mazaios et Mithridatès aux patrons. (Partie gauche) À l'empereur César Auguste, fils du divin (Jules), grand pontife, consul pour la $12^{\mathrm{e}}$ fois, revêtu de la puissance tribunicienne pour la $20^{\mathrm{e}}$ fois et à Livie, (épouse) de César Auguste. (Partie droite) À Marcus Agrippa, fils de Lucius, consul pour la $3^{\mathrm{e}}$ fois, général victorieux, revêtu de la puissance tribunicienne pour la $6^{\mathrm{e}}$ fois et à Julie, fille de César Auguste.

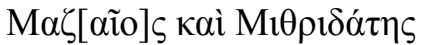

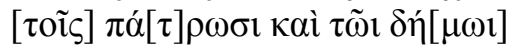

Mazaios et Mithridatès aux patrons et au peuple.

Élevée peu avant notre ère, cette porte monumentale à la gloire d'Auguste et d'Agrippa permettait de pénétrer dans l'agora basse de la ville. Les motivations de Mazaios et de Mithridatès, semblent avoir été nombreuses. S'il s'agissait d'un geste de gratitude pour ceux qui les avaient affranchis, l'édification de ce monument permettait également aux deux hommes de se poser en bienfaiteurs de la cité qu'ils contribuaient à embellir. De plus, ils apparaissaient aux yeux de leurs concitoyens comme de riches notables qui, par leurs liens avec l'empereur, pouvaient servir d'intermédiaire entre la cité et le pouvoir romain.

Il est remarquable que les deux noms soient iraniens. Mithridatès peut être interprété comme *MiOridasta (" Main de

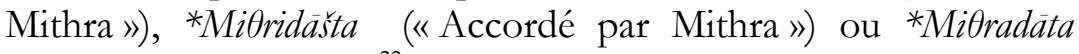
(«Donné par Mithra ») ${ }^{22}$. Cette dernière étymologie semble être la plus plausible. Il s'agit d'un anthroponyme mithriaque qui fut porté par de nombreux souverains asiatiques dans les siècles qui suivirent la chute de l'empire achéménide. Quant à Mazaios, il portait un anthroponyme construit à partir du nom du principal dieu iranien, Ahuramazdā. Selon J. Tavernier, on peut suggérer que Mazaios est la grécisation d'un hypocoristique construit sur un nom tel que *Mazda-pāta ("Protégé par Mazda») ou *Mazdadàta ("Donné par Mazda ») ${ }^{23}$. Au IV ${ }^{\mathrm{e}}$ siècle, un satrape perse qui gouverna successivement la Cilicie puis la Babylonie avant de se rallier à Alexandre, porta le nom de Mazaios.

${ }^{22}$ R. SCHMITT, « Die theophoren Eigennamen mit altiranisch *MiOra- » in Etudes Mithriaques, Actes du $2 e$ Congrès International, Tébéran, du $1^{e r}$ an 8 septembre 1975, Acta Iranica $n^{\circ} 17$ (1978), p. 409 et Iranisches Personennamenbuch V, Wien, 1982, p. IV/32 ; J. TAVERNIER, Iranica in the Achaemenid period, Leuven, 2007, p. 485.

${ }^{23}$ J. TAVERNIER, Iranica in the Achaemenid period, Leuven, 2007, p. 244. 


\section{Epitaphe de Mithradatès}

Plaque trouvée dans le voisinage du théâtre. Datation : époque impériale (règne d'Auguste ?).

Éditions et commentaires : H. ENGELMANN - D. KNIBBE - R. MERKELBACH, Die Inschriften von Ephesos III, Bonn, 1980, nº51 ; D. MCCABE R.N. ElliotT - A. Hilton - C. Redmond, Ephesos Inscriptions. Texts and list, Princeton, 1991, n²486.05 ; R. A. KEARSLEY - T. V. EVANS, 2001, Greeks and Romans in Imperial Asia. Mixed Language Inscriptions and Linguistic Evidence for Cultural Interaction until the End of $A D$ III (Inschriften griechischer Städte aus Kleinasien 59), Bonn, 2001, nº19.

\section{Mithradates Agrippae l(ibertus)}

Mithradatès affranchi d'Agrippa.

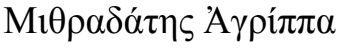 $\dot{\alpha} \pi \varepsilon \lambda \varepsilon v \dot{\theta} \theta \varepsilon \rho \varsigma[\zeta \tilde{n}]$}

Mithradatès affranchi d'Agrippa. Qu'il vive.

Cette épitaphe marquait l'emplacement de la tombe d'un certain Mithradatès, affranchi d'Agrippa. On suppose généralement qu'il s'agit du même homme qui fit édifier, avec Mazaios, la porte monumentale que nous venons de voir. Toutefois, il faut noter la différence de graphie entre Mithridatès et Mithradatès. Le nom étant mentionné deux fois dans chaque inscription (en latin puis en grec), une erreur du lapicide est peu probable. À moins donc qu'il ne s'agisse d'un deuxième affranchi d'Agrippa, il faut admettre qu'il y avait une certaine liberté de graphie. Le fait que cet homme ait voulu se faire inhumer à Éphèse peut indiquer qu'il était originaire de cette ville.

\section{B. Inscriptions funéraires}

Outre l'épitaphe de Mithradatès, trois inscriptions funéraires mentionnent des habitants d'Éphèse portant un nom iranien.

\section{Tombe de [...] Cyrus et de Vedius Tatianus}

Stèle de marbre blanche trouvée en remploi dans une cabane de la citadelle turque. 20 x $51 \mathrm{~cm}$. Datation : époque impériale.

Éditions et commentaires : R. MERKELBACH - J. NOLLE, Die Inschriften von Ephesos VI, Bonn, 1980, n²246B ; D. MCCABE - R.N. ELLIOTT - A. HiLton - C. Redmond, Ephesos Inscriptions. Texts and list, Princeton, 1991, n²510.

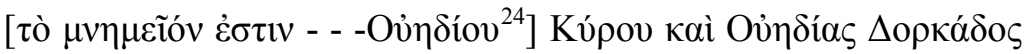

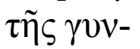

${ }^{24} \mathrm{Je}$ suis ici l'hypothèse de R. MerkelbaCH - J. NOLLE, Die Inschriften von Ephesos VI, Bonn, 1980, p. 154 selon laquelle il faut lire OY]H $\Delta$ IOY plutôt que ]TATOY. 


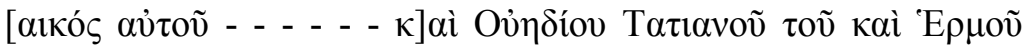
$\varphi \uparrow \lambda \circ \sigma \varepsilon \beta \alpha ́ \sigma-$

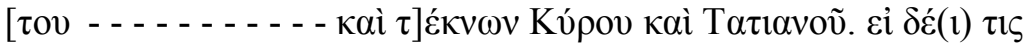
$\tau \mathrm{o} \lambda \mu \eta \dot{-}$

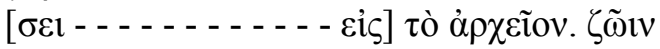

[(Ceci) est le tombeau de ... Védius] Cyrus et de Védia Dorcas son épouse (...) et de Védius Tatianus, alias Hermès, qui aime l'empereur, et des enfants de Cyrus et Tatianus. Si on (...) ose (...) qu'ils se rendent au lieu où siègent les magistrats. Qu'ils vivent tous les deux.

Cette inscription est l'épitaphe qui figurait sur la tombe d'une famille de notables d'Éphèse. Ce monument funéraire était destiné à abriter les restes de Védius Cyrus, son épouse Dorcas, Védius Tatianus et de leurs enfants respectifs. Le premier porte, en guise de cognomen l'anthroponyme Cyrus célèbre pour avoir été le nom du fondateur de l'empire perse, Cyrus II l'Ancien, ainsi que du fameux prince achéménide, Cyrus le Jeune. La signification de ce nom a été très discuté mais il est possible qu'il vienne de l'élamite Kurašs signifiant «Qui accorde du soin ».

\section{Publius Cordius Pharnace}

Plaque de marbre blanc trouvée sur le versant ouest de la colline d'Ajasoluk. 19 x 40,5 x 8cm ; Hauteur des lettres : 1,6cm. Datation : époque romaine.

Éditions et commentaires: R. MERKELBACH - J. NOLLE, Die Inschriften von Ephesos VI, Bonn, 1980, n²240A ; D. MCCABE - R.N. ElLIOTT - A. HiLTON - C. Redmond, Ephesos Inscriptions. Texts and list, Princeton, 1991, n²421; R. A. Kearsley - T. V. Evans, 2001, Greeks and Romans in Imperial Asia. Mixed Language Inscriptions and Linguistic Evidence for Cultural Interaction until the End of AD III (Inschriften griechischer Städte aus Kleinasien 59), Bonn, 2001, n³31.

$$
\begin{aligned}
& \text { P. Cordius } \\
& \text { Pharnaces [[vivat]] } \\
& \text { [vixi]t annos LXXXVI } \\
& {[\pi \circ \lambda \lambda] \grave{\alpha} \dot{\alpha} \gamma \alpha \pi \omega ́ \mu[\varepsilon v o \varsigma]}
\end{aligned}
$$

Publius Cordius Pharnace a vécu 86 ans très aimé.

Cette inscription, qui a la particularité d'être bilingue, conserve le souvenir d'un homme, nommé Publius Cordius Pharnace, qui mourut octogénaire. Le cognomen Pharnace est à l'origine un nom iranien célèbre pour avoir été porté par des satrapes de Daskyleion et des rois du Pont. Plus précisément, il s'agirait d'un hypocoristique en -aka lié au mot iranien Farnah signifiant « Gloire ».

${ }^{25}$ J. TAVERnIER, Iranica in the Achaemenid period, Leuven, 2007, p. 528.

26 A. H. M. Stonecipher, Graeco-Persian Names, NewYork/Cincinnati/Chicago, 1918, p. 67-68. 


\section{Claudius fils de Mithridatès}

Inscription funéraire trouvée à Éphèse. Datation : époque impériale.

Éditions et commentaires : H. ENGELMANN - D. KNIBBE - B. IPLIKÇIOGLU, "Neue Inschriften aus Ephesos, XI », Jahreshefte des Österreichischen Archäologischen Instituts 59 (1989), $\mathrm{n}^{\circ} 51$; Supplementum Ephesium, $2663 * 9$.

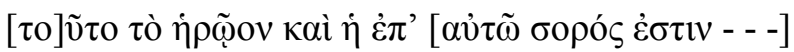

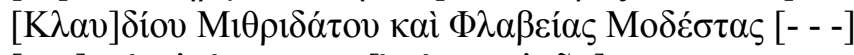

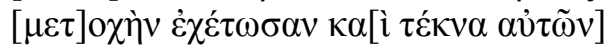

Ce tombeau et l'urne au-dessus est à (...) Claudius fils de Mithridatès et Flavia Modesta (...) que leurs enfants aussi y participent.

Cette inscription nous fait connaitre un nouveau Mithridatès. Si l'origine iranienne de ce nom est indubitable, il est difficile d'avancer que son porteur est un descendant de la diaspora achéménide. Il est en effet tout à fait romanisé.

C. Noms iraniens dans les listes de kourètes

À Éphèse existait une association cultuelle nommée le collège des kourètes, qui tirait son nom de divinités mineures, les kouretai, censées avoir protégé Artémis et son frère Apollon à leur naissance ${ }^{27}$. Chaque année, les membres de ce collège quittaient le prytanée en traversant la rue, désormais appelée "Rue des kourètes », pour aller participer au culte d'Artémis. Les noms des individus membre de ce collège étaient conservés sur de longues listes gravées sur les murs du prytanée. Bien qu'être kourète fut assez honorifique, F. Kirbihler note que ceux-ci étaient issus d'un « milieu plus composite, moins 'notabilisé' que celui de la plupart des magistratures ${ }^{28}$. En effet, si les magistrats d'Éphèse à l'époque impériale sont issus de familles de notables, les kourètes pouvaient être d'origine moins aristocratique. Parmi les membres de ce collège dont le nom nous est parvenu, trois portent un nom d'origine iranienne.

\section{Dionysios fils de Charésios petit-fils de Mithridatès}

Inscription trouvée sur un tambour de colonne au sud des Bains de Varus. Celui-ci faisait à l'origine partie du portique du prytanée. 104,5 cm de haut sur $110 \mathrm{~cm}$ de diamètre ; Hauteur des lettres : entre 1,5 et $4 \mathrm{~cm}$. Datation : époque impériale (vers 54 et $59)$.

${ }^{27}$ STRABON, Géographie, XIV, 1, 20.

${ }^{28}$ F. KIRBIHLER, Les notables d'Éphèse, essai d'histoire sociale (133 av. J.-C. - 262 ap. J.-C.), Tours, 2003, p. 153. 
Éditions et commentaires : F. MILTNER, «Vorläufiger Bericht über die Ausgrabungen in Ephesos », Jahreshefte des Österreichischen Archäologischen Instituts 44 (1959), n¹46 ; H. Engelmann - D. KnibBe - R. Merkelbach, Die Inschriften von Ephesos IV, Bonn, 1980, $\mathrm{n}^{\circ} 1008$; D. KNIBBE, Forschungen in Ephesos IX, Faszikel 1.1, Wien, 1981, NB8 ; D. MCCABE - R.N. ELLIOTT - A. Hilton - C. Redmond, Ephesos Inscriptions. Texts and list, Princeton, 1991, $n^{\circ} 454$.

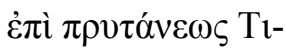

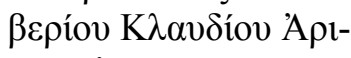

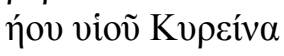

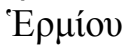

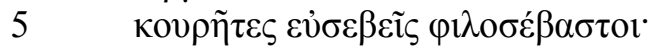

Suit la liste des kourètes, dont :

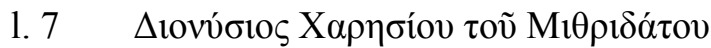

Sous la prytanie de Tibérius Claudius Hermias fils d'Ariès Kureina, (étaient) kourètes, pieux et fidèles aux Augustes :

Suit la liste des kourètes, dont :

1. 7 Dionysios fils de Charésios, petit-fils de Mithridatès

\section{2. [... J]ulius Pharnakès}

Inscription trouvée sur un tambour de colonne au sud des Bains de Varus. Celui-ci faisait à l'origine partie du portique du prytanée. $90 \mathrm{~cm}$ de haut sur $115 \mathrm{~cm}$ de diamètre; hauteur des lettres entre 2 et 2,4 cm. Datation : époque impériale (vers 80-95).

Éditions et commentaires : H. ENGELMANN - D. KNIBBE - R. MERKELBACH, Die Inschriften von Ephesos IV, Bonn, 1980, n¹047 ; D. KNIBBE, Forschungen in Ephesos IX, Fasqikel 1.1, Wien, 1981, N${ }^{\circ}$ B47 ; D. MCCABE - R.N. ElliotT - A. Hilton - C. ReDmond, Ephesos Inscriptions. Texts and list, Princeton, $1991, \mathrm{n}^{\circ} 443$.

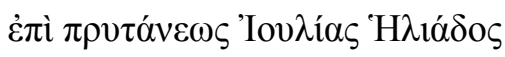

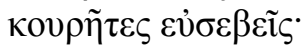

Suit la liste des kourètes, dont :

1. 6

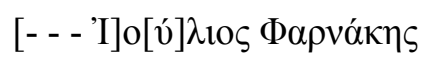

Sous la prytanie de Iulia Hélias, (étaient) de pieux kourètes :

Suit la liste des kourètes, dont :

1. 6

$$
\text { (...) Iulius Pharnakès }
$$

\section{Mithridatès fils de Spendôn}

Plaque de marbre blanc en quatre fragments ( $a, b, c$ et $d)$ trouvés à Éphèse en divers lieux : les fragments b et $\mathrm{c}$ dans les décombres du portique du prytanée, le fragment a parmi les pavés 
devant le théâtre et le fragment $\mathrm{d}$ parmi les pavés devant la bibliothèque de Celsus. Ils sont désormais rassemblés dans le dépôt de la terrasse de Domitien. Datation : époque impériale (vers 180192).

Éditions et commentaires : F. MiLTNER, «Die Österreichischen Ausgrabungen in Ephesos im Jahre 1958 », Anzeiger der Österreichischen Akademie der Wissenschaften 96 (1959), $\mathrm{n}^{\circ} 41 \mathrm{f}$ (fragment a uniquement) ; H. WANKEL, Die Inschriften von Ephesos I, Bonn, 1979, $\mathrm{n}^{\circ} 47$; D. KNIBBE, Forschungen in Ephesos IX, Faszikel 1.1, Wien, 1981, N 54 ; D. MCCABE - R.N. ElLIOTT - A. HILTON - C. REDMOND, Ephesos Inscriptions. Texts and list, Princeton, 1991, n²42.

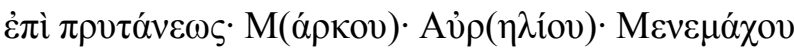

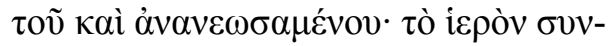

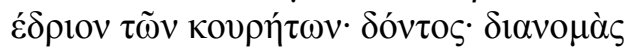

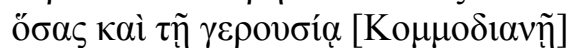

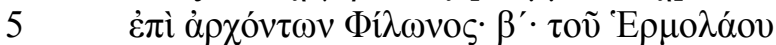

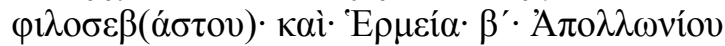

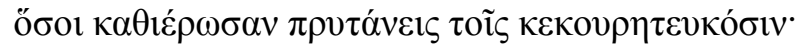

Suit une liste des kourètes dont :

1. 61

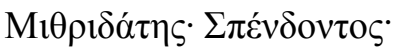

Sous la prytanie de M(arcus) Aur(élius) Ménémachos, celui qui a été aussi le restaurateur du conseil sacré des kourètes après avoir fait des distributions aussi nombreuses que celles prodiguées à la Gérousie commodienne, sous le second archontat de Philôn fils d'Hermolas, qui aime l'empereur, et d'Hermeias fils d'Apollônios ${ }^{29}$, des prytanes en assez grand nombre consacrèrent (cette stèle) aux kourètes sortis de charges.

Suit une liste des kourètes dont :

\section{61 Mithridatès fils de Spendôn}

Les anthroponymes relevés dans ces listes ont déjà été rencontrés. Il s'agit de Mithridatès, à deux reprises, et de Pharnakès. Comme nous l'avons dit, il s'agit de noms iraniens célèbres pour avoir été portés par des souverains de l'époque hellénistique.

E. Marcus Aurunceius Vedius Mithridatès

\section{Inscription du pronaos du sanctuaire de Némésis}

Bloc de marbre blanc en quatre fragments jointifs retrouvé dans un mur d'époque tardive mais provenant du théâtre : $65 \mathrm{x}$ $51 \times 25 \mathrm{~cm}$; Hauteur des lettres 0,025. Datation : époque impériale (vers 210-240).

Éditions et commentaires : R. MERKELBACH - J. NOLLE, Die Inschriften von Ephesos VI, Bonn, 1980, n²042 ; D. MCCABE - R.N. ELLIOTT - A. HiLTON -

29 Précisons que la traduction française laisse une ambiguïté : il s'agit du second archontat de Philôn mais aussi le second d'Hermeias. 
C. ReDmond, Ephesos Inscriptions. Texts and list, Princeton, 1991, n 406 ; M. B. Hornum, Nemesis, the Roman State, and the Games, Leiden, 1993, n²39.

\begin{tabular}{|c|c|}
\hline \multicolumn{2}{|r|}{ 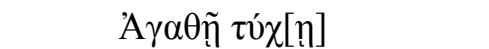 } \\
\hline 2 & 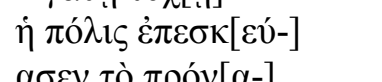 \\
\hline 4 & 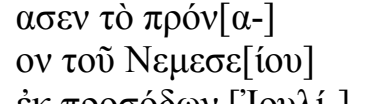 \\
\hline & 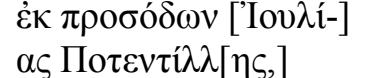 \\
\hline & $\gamma \rho \alpha \mu \mu \alpha \tau \varepsilon v ́ o v[\tau \mathrm{O} \varsigma]$ \\
\hline 8 & 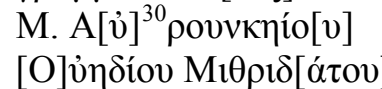 \\
\hline
\end{tabular}

A la bonne Fortune, la cité a restauré le pronaos du sanctuaire de Némésis sur les revenus de Julia Potentilla, M(arcus) Auruncéius Védius Mithridatès étant secrétaire.

\section{Décret honorifique}

Bloc de marbre gris-bleu trouvé en remploi dans l'église Saint-Jean dans un pilier de la colonnade sud. 94,5 x 161 x 40,5 $\mathrm{cm}$ (hauteur des lettres $3 \mathrm{~cm}$ ) Datation : époque impériale (vers 210-240).

Éditions et commentaires : J. KEIL, «Vorläufiger Bericht über die Ausgrabungen in Ephesos ", Jahreshefte des Österreichischen Archäologischen Institutes in Wien 25 (1929), p.17 et Forschungen in Ephesos IV, Faszikel 3, Wien, 1951, n³6 (pl. LXV) ; R. MeriÇ - R. MerkelBACH - J. NOlle - S. ŞAHIN, Die Inschriften von Ephesos VII, 2, Bonn, 1981, n 4336 ; G. H. R. Horsley, New Documents Illustrating Early Christianity IV, North Ryde, 1987, n¹54 ; D. MCCABE - R.N. ElliotT - A. Hilton - C. REDMOND, Ephesos Inscriptions. Texts and list, Princeton, 1991, n¹068; Supplementum Epigraphicum Graecum IV, n523.

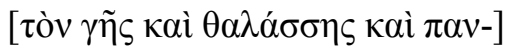

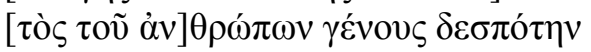

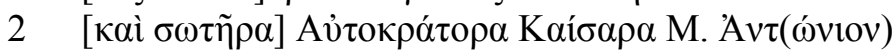

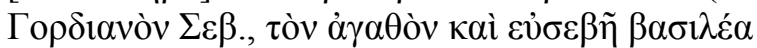

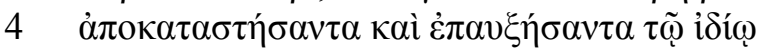

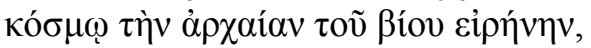

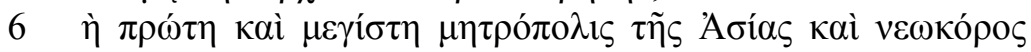
$\tau \tilde{\eta} \varsigma$

A

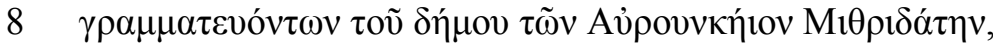

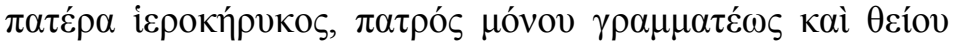

кaì

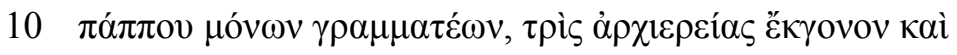

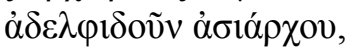

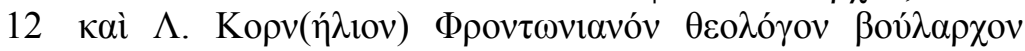
$\pi \alpha \tau \dot{\varepsilon} \rho \alpha$ i $\varepsilon \rho o-$

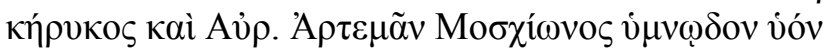

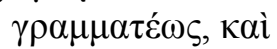

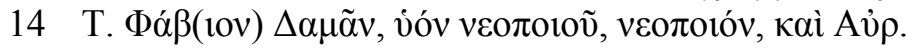

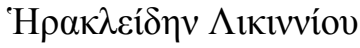

\footnotetext{
${ }^{30}$ Je restitue le upsilon sans doute oublié par le lapicide.
} 


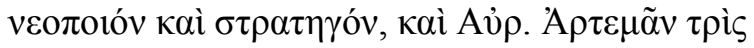
$\varphi \imath \lambda \circ \sigma \varepsilon \dot{\beta} \beta \alpha \sigma \tau \mathrm{v}$

La cité d'Éphèse, première et très grande métropole d'Asie, néocore d'Artémis et deux fois néocore des Augustes, (honore) l'empereur César M(arcus) Ant(onius) Gordianus Auguste, maitre et sauveur de la terre, de la mer et de toute l'humanité, le bon et pieux empereur ayant rétabli et augmenté, pour le monde qui est sien, l'ancienne paix dans laquelle nous vivions et, parmi ceux qui étaient secrétaires du peuple, Auruncéius Mithridatès, père d'un héraut sacré, dont le père, l'oncle et le grand-père ont été secrétaires uniques (du peuple), descendant d'une femme trois fois grande prêtresse et neveu d'un asiarque ; L(ucius) Cornélius Fontanianus, devin et président du Conseil, père d'un héraut sacré; Aur(élius) Artémas fils de Moschion, chanteur d'hymne et fils d'un secrétaire, T(itus) Fab(ius) Damas, néope et fils de néope; Aur(élius) Héracleidès fils de Licinius, néope et stratège et Aur(élius) Artémas ami de trois Augustes ${ }^{31}$.

Lorsque dans les années 190 de notre ère, le Sénat romain fut partiellement renouvelé, des familles de notables asiatiques quittèrent leurs cités d'origine pour s'installer à Rome. Ce vide créé dans les provinces poussa l'émergence de nouvelles familles dont celle des Aurunceii qui atteignit son apogée dans la première moitié du III $^{\text {e }}$ siècle. Peut-être originaire de Campanie, elle se lia à Éphèse à d'autres familles de notables, comme les $V e d i i^{32}$. Notre Marcus Auruncéius Védius Mithridatès, qui exerça la fonction de secrétaire et fut honoré par la cité à l'époque de Gordien III, s'inscrit dans cette histoire familiale. L'élément iranien de son nom est cependant difficile à expliquer. On peut soit supposer qu'un mariage fut contracté, à une époque indéterminée, avec une famille descendante de colons iraniens, soit considérer que ce nom avait perdu toute connotation ethnique et n'avait été choisi que pour sa célébrité.

\section{F. Inscriptions diverses}

\section{Mithridatès fils de Mithrès et Myron fils de Mithridatès}

Nombreux fragments trouvés en divers endroits d'Éphèse et provenant sans doute à l'origine de l'Artémision, peut-être du mur du péribole. Il s'agit d'une liste de souscripteurs ayant donné de l'argent à la banque de l'Artémision dans un but inconnu en

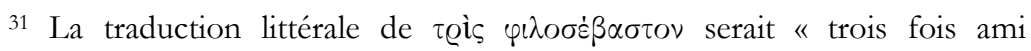
d'Auguste ». Si l'empereur honoré est bien Gordien III, les deux autres Augustes en question pourraient être son grand-père et son oncle Gordien Ier et Gordien II. Aurélius Héracleidès serait donc un partisan de la dynastie gordienne qui allait se révéler si éphémère.

${ }^{32}$ F. KIRBIHLER, «Stratégies familiales, généalogies et survie de familles en lien avec Éphèse de la Carie à Rome (fin IIe-IVe siècles) » in Ch. BADEL \& Ch. SETTIPANI, Les stratégies familiales dans l'Antiquité tardive, Paris, 2012, p. 284-287. 
raison d'une lacune du texte. Datation : époque impériale (23-25 de notre ère).

Éditions et commentaires : Ch. BÖRKER, Die Inschriften von Ephesos $V$, Bonn, 1980, n¹687 (publication de tous les fragments) ; D. MCCABE - R.N. Elliott - A. Hilton - C. ReDmond, Ephesos Inscriptions. Texts and list, Princeton, 1991, $\mathrm{n}^{\circ} 241$; L. MIGEOTTE, Souscriptions publiques dans les cités grecques, Québec/Genève, 1992, nº70 ; Supplementum Epigraphicum Graecum XLVII, n¹618; XLVIII, n¹382 ; XLIX, n¹464 et 2432 ; XL, n¹133) ; F. KIRBIHLER, Les notables d'Éphèse, essai d'bistoire sociale (133 av. J.-C. - 262 ap. J.-C.), Tours, 2003, p.942-956.

- Fragment 9

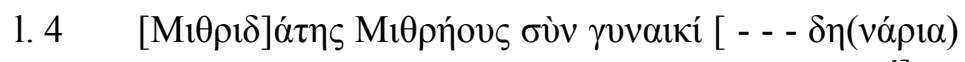

$\left.i^{\prime}\right]$

Mithridatès fils de Mithrès avec sa femme 10 deniers.

- Fragment 14

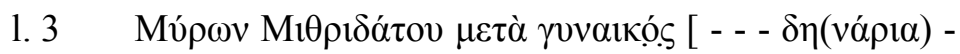
$\left.--^{\prime}\right]$

Myron fils de Mithridatès avec sa femme (?) deniers

Cette liste de noms comprend trois noms mithriaques. On peut considérer soit qu'il s'agit de trois individus distincts, soit que nous sommes en présence d'une famille connue sur trois générations. Le grand-père se serait appelé Mithrès, le père Mithridatès et le fils Myron. Si cette seconde hypothèse est vraie, leur goût pour les noms mithriaques est remarquable. Peut-être doit-on les considérer comme des descendants de colons installés à Éphèse ? Quoi qu'il en soit, ils ne semblent pas avoir été très aisés car ils sont parmi les plus faibles contributeurs de la liste (les donations allant de 2500 à 10 deniers).

\section{Mazaios agoranome}

Inscription trouvée sur l'agora d'Éphèse. Datation : époque impériale (vers 100-220).

Éditions et commentaires : H. ENGELMANN - D. KNIBBE - R. MERKELBACH, Die Inschriften von Ephesos III, Bonn, 1980, n933a ; D. MCCABE - R.N. ElLIOTT - A. Hilton - C. REDMOND, Ephesos Inscriptions. Texts and list, Princeton, $1991, \mathrm{n}^{\circ} 1939$.

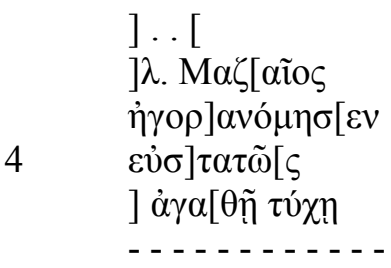

[...Iu]l(ius) Mazaios a été agoranome d'une manière posée. A la bonne Fortune. 
Cette inscription très mutilée nous fait connaître un agoranome nommé Iulius (?) Mazaios. A moins qu'il ne s'agisse d'un descendant d'affranchi, il est probable que sa famille ait obtenu la citoyenneté au début de l'empire. Bien que cela soit purement hypothétique, il est même envisageable qu'il soit un descendant du Mazaios qu'Auguste avait affranchi.

\section{Dédicace de Philippe Mazaios}

Architrave découverte à l'angle nord-ouest de l'agora d'Éphèse par D. Knibbe. Datation : inconnue.

Éditions et commentaires : D. KNIBBE, « Neue Inschriften aus Ephesos VVII », Jahreshefte des Österreichischen Archäologischen Institutes in Wien 50 (1972-75), n`12 ; Supplementum Epigraphicum Graecum XXVI, n¹275; Ch. BÖRKER - R. MERKELBACH, Die Inschriften von Ephesos II, Bonn, 1979, n 434 ; D. MCCABE R.N. ElliotT - A. Hilton - C. ReDmOnd, Ephesos Inscriptions. Texts and list, Princeton, 1991, n³12 ; A.-F. JACCOTTET, Choisir Dionysos. Les associations dionysiaques on la face cachée du Dionysisme. II. Documents, Kilchberg, 2003, n¹44.

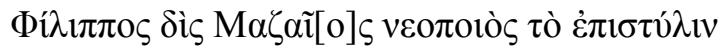 $\tau \tilde{\omega} \mathrm{B} \alpha \chi \chi \varepsilon \dot{\varepsilon} \omega$ à $v \varepsilon \dot{\theta} \theta \eta \kappa \varepsilon v$}

Philippe Mazaios, deux fois néope, a consacré l'architrave à Bacchus.

Le dédicant de cet inscription porte lui aussi le nom iranien Mazaios. Il semble faire partie de l'élite municipale de la cité car il a exercé par deux fois la fonction de magistrat financier, les néopes.

\section{Phar[nakès] et Mithrès}

Fragment d'inscription (dépôt $\mathrm{n}^{\circ}$ 918) provenant d'une fontaine d'Éphèse. 22 x 51 x $39 \mathrm{~cm}$; Hauteur des lettres $1,9 \mathrm{~cm}$. Datation : inconnue.

Éditions et commentaires : Ch. BÖRKER, Die Inschriften von Ephesos $V$, Bonn, 1980, n¹814 ; D. MCCABE - R.N. Elliot'T - A. Hilton - C. REDMOnd, Ephesos Inscriptions. Texts and list, Princeton, 1991, nº3692.

$$
\begin{aligned}
& \text { ]ov } \Phi \alpha \rho[\text { vókov } \quad \text { (...) de Pharnace (...) }
\end{aligned}
$$

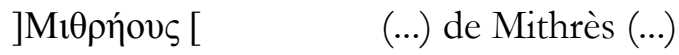

\section{Orontès, fils de Pisistrate}

Fragment trouvé dans un vestibule à Scala Nova (actuel Kuşadasi). Cette ville, fondée à l'époque byzantine, avait vocation à servir de nouveau port à Éphèse. En effet, avec l'apport continu des alluvions du Caystre, le front de mer s'était éloigné de la ville. 37 x 28 x $15 \mathrm{~cm}$. Hauteur des lettres $8 \mathrm{~mm}$. Datation : inconnue.

Éditions et commentaires : R. MERIÇ - R. MERKELBACH - J. NOLLE - S. ŞAHIN, Die Inschriften von Ephesos VII, 1, Bonn, 1981, n³131 ; D. MCCABE - 
R.N. ElliotT - A. Hilton - C. Redmond, Ephesos Inscriptions. Texts and list, Princeton, 1991, nº04 ; Supplementum Epigraphicum Graecum XXXI, n¹580.

$[---] \circ \lambda_{1} \delta[---]$

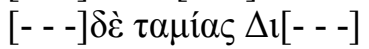

[- - - $\pi \rho \varepsilon \sigma \beta \varepsilon v \tau \alpha \tilde{\varsigma} \varsigma[--$ - ]

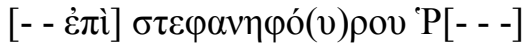

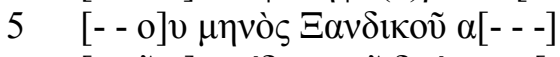

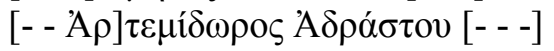

[- - H]

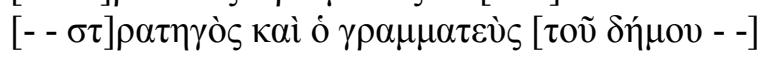

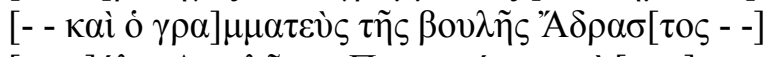

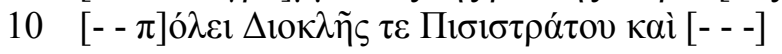

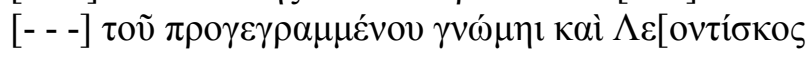

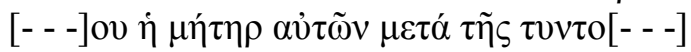

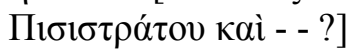

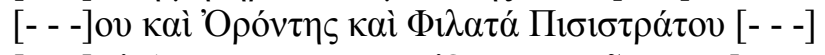

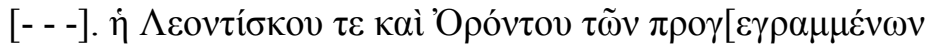

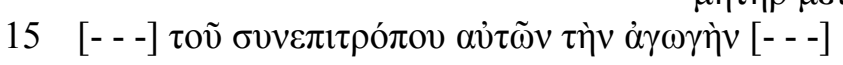
$\mu \eta \dot{\tau} \eta \mu \varepsilon \tau \dot{\alpha}--]$

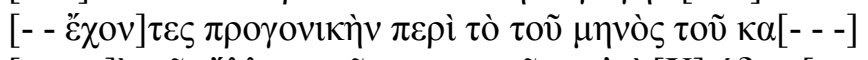

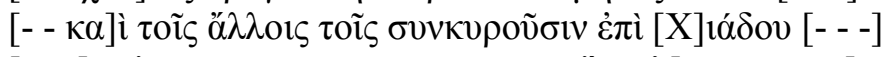

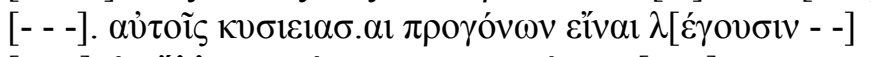

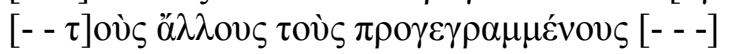

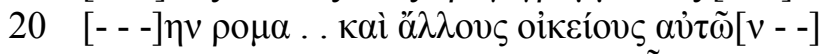

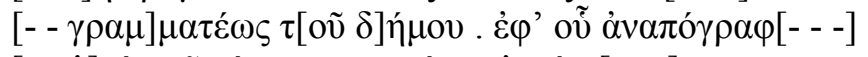

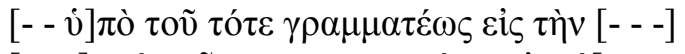

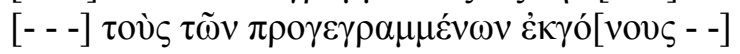

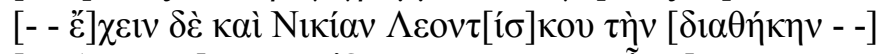

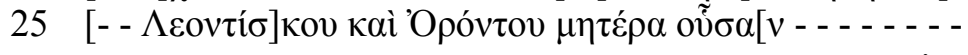

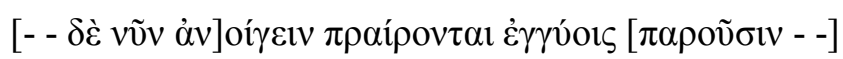

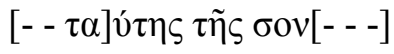

(...) l'intendant (...) aux ambassadeurs (...) sous (...) stéphanéphore (...) le mois de Xandicos (...) Artémidôros fils d'Adraste (...) Hérodote fils d'Artémon (...) le stratège et le secrétaire du peuple (...) et le secrétaire du Conseil Adraste (...) pour la cité Dioclès fils de Pisistrate et (...) par décision de (...) cidessus mentionné et Léontiscos fils de Pisistrate et (...) leur mère avec la (...) et Orontès et Philata, fille de Pisistrate (...) la mère de Léontiscos et d'Orontès mentionnés plus haut (...) avec (...) de leur co-tuteur (...) l'éducation ancestrale (...) le mois de (...) les autres choses qui arrivent sous Chiadès (...) ils disent que cela appartient à leurs ancêtres (...) les autres qui ont été ci-dessus mentionnés et d'autres qui leur sont apparentés (...)secrétaire du peuple (...) sous lequel il a été enregistré par le secrétaire de l'époque (...) les descendants des personnes ci-dessus mentionnées (...) que Nicias fils de Léontiscos ait en sa possession la succession (...) qui est mère de Léontiscos et d'Orontès (...) se charge d'ouvrir (...) en présence de garants (...).

Cette inscription, qui n'est peut-être pas originaire d'Éphèse mais plutôt des terres alentours, est très fragmentaire et la lecture 
en est trop incertaine pour permettre un long commentaire. Tout juste pouvons-nous comprendre qu'il s'agit d'une querelle de succession dans la famille d'un certain Pisistrate. Outre son épouse, nous lui connaissons trois enfants : Orontès, Léontiscos et Philata. Le sujet de la querelle semble avoir été les possessions de Pisistrate ainsi que la tutelle sur ses enfants. Orontès est clairement un nom iranien. Il s'agit peut-être d'un hypocoristique construit sur l'adjectif * arvanta signifiant « rapide $»^{33}$. Cependant, cet homme est issu d'une famille dont tous les autres membres connus portent des nom grecs. Il parait donc hasardeux d'avancer que cette famille est issue de l'ancienne diaspora.

\section{Fragment au nom de Sisinnios}

Fragment d'inscription trouvé à Éphèse. Datation : début de l'époque byzantine.

Éditions et commentaires : H. ENGELMANN - D. KNIBBE - R. MERKELBACH, Die Inschriften von Ephesos IV, Bonn, 1980, n¹298 ; D. MCCABE - R.N. ElliotT - A. Hilton - C. ReDmOnd, Ephesos Inscriptions. Texts and list, Princeton, 1991, $\left.\mathrm{n}^{\circ} 3155\right)$.

$$
\begin{aligned}
& \text { [.] }
\end{aligned}
$$

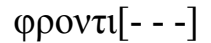

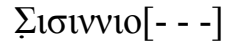

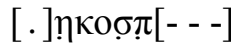

$$
\begin{aligned}
& \text { (...) Sisinnios (...) }
\end{aligned}
$$

Cette inscription est trop fragmentaire pour appeler un long commentaire. Toutefois, il est intéressant pour nous de constater que le seul mot lisible soit un nom iranien : Sisinnios, variante de Sisinès. Comme nous l'avons écrit dans un précédent article, il s'agit de la transcription grecque du nom vieux-perse ${ }^{*}$ Čiçina, hypocoristique en ina d'un anthroponyme construit sur le terme *Ciça signifiant « lignage » ou « brillant $»^{34}$.

\section{Prière pour Sisinès}

Inscription chrétienne trouvée à Éphèse. Datation : époque impériale.

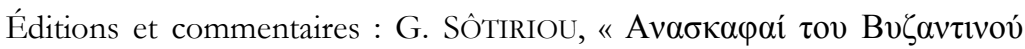

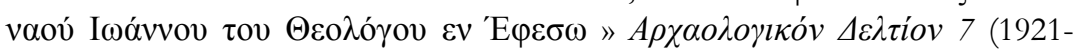
1922), p. 111-112 ; J. KEIL, Forschungen in Ephesos IV, Faszikel 3, Wien, 1951, n¹4 ; R. Meriç - R. MerkelBACH - J. Nolle - S. ŞAhIn, Die Inschriften von Ephesos VII, 2, Bonn, 1981, n4314 ; D. MCCABE - R.N. ELLIOTT - A.

$33 \mathrm{Ph}$. HuYSE, Iranische Namen in den griechischen Dokumenten Ägyptens (Iranisches Personennamenbuch V/6a), Wien, 1991, p. 39 ; R. SCHMITT, Iranische Namen in ägytischen Nebenüberlieferungen (Iranisches Personennamenbuch VIII), Wien, 2013, p. 38.

34 J. TAVERNIER, Iranica in the Achaemenid period, Leuven, 2007, p. 551 ; F. BOUZID-ADLER, "Noms iraniens dans l'onomastique de la ville de Sardes ", BABELAO 3 (2014), p. 22. 
Hilton - C. Redmond, Ephesos Inscriptions. Texts and list, Princeton, 1991, n²973; Supplementum Epigraphicum Graecum IV, n 551.

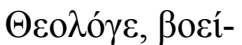

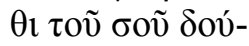 \\ $\lambda$ ov $\Sigma$ เøเvท́ov \\ 出 \\ $5 \quad \kappa \grave{\varepsilon} \tau \tilde{\imath} \varsigma \mu \imath \tau \rho \grave{\varsigma} \alpha^{\prime} \tau o \tilde{v}$.
}

(Saint Jean) Théologien, viens au secours de ton serviteur Sisinès (croix) et de sa mère.

Ce texte est une prière adressée par un certain Sisinès, dont le nom est, comme nous venons de le voir, iranien, à saint Jean

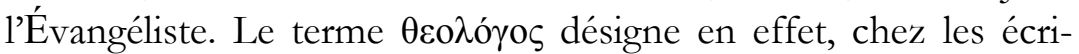
vains ecclésiastiques, ce disciple qui, selon la tradition, serait mort et aurait été inhumé à Éphèse. Un martyrion fut érigé abrité par deux basiliques successives connues sous le vocable de «SaintJean le Théologien ». Sisinès implore l'aide de l'apôtre à la fois pour lui et pour sa mère.

\title{
Exploitation et perspectives
}

Ce relevé anthroponymique montre clairement la difficulté de trouver des traces de la diaspora impériale achéménide. Si un nombre assez conséquent d'Éphésiens portèrent des noms iraniens grécisés ou romanisés, la majorité de ces attestations sont de très loin postérieures à la domination achéménide. Dès lors, faire le lien entre tel ou tel cas épigraphique et la présence iranienne attestée à l'époque classique par les auteurs anciens est délicat. Certes, il n'est pas impossible que certains des individus que nous avons vu soient des descendants de la diaspora impériale achéménide. Cependant, d'autres faits peuvent expliquer la présence de ces noms à Éphèse. Il peut par exemple s'agir d'anciens esclaves venus d'Iran et finalement affranchis en Ionie où ils se seraient installés. Outre Mazaios et Mithridatès, les affranchis d'Auguste et d'Agrippa, cette situation a peut-être concerné certains des individus portant le nom Mithrès. En effet, comme le rappelle M.-F. Baslez, il s'agit d'un anthroponyme d'esclavage assez courant dans le monde grec aux époques hellénistiques et, surtout, romaines ${ }^{35}$. Il n'est donc pas impossible que certains parmi les trois Mithrès que nous avons vus, et à propos desquels nous sommes très mal informés, soient d'anciens esclaves.

M.-F. Baslez mettait également en garde contre la mode, chez les notables des cités grecques, d'adopter des noms célèbres par

\footnotetext{
${ }^{35}$ M.-F. BASLEZ, « Présence et traditions iraniennes dans les cités de l'Égée ", Revue des études anciennes 87 (1985), p.147-148 ; voir aussi M. LAMBERTZ, « Die griechischen Sklavennamen ", Jahresberichte LVII (1906-1907), p. 27 ; L. ROBERT, Études épigraphiques et philologiques, Paris, 1938, p. 211-212 et Hellenica XIII, Paris, 1965, p. 94.
} 
l'histoire ou la littérature ${ }^{36}$. Parmi ces noms célèbres pouvaient entre autre se trouver des anthroponymes de souverains ou de généraux iraniens. Or, dans le corpus que nous venons de voir, un nombre relativement important d'individus portent des noms royaux. Le plus courant est Mithridatès/Mithradatès qui apparaît six ou sept fois ${ }^{37}$. Ce nom fut porté par un nombre important de souverains parthes, arméniens, ibères, du Bosphore et de Commagène. Cependant, les plus fameux sont ceux qui régnèrent sur le royaume du Pont, en particulier Mithridatès VI Eupatôr célèbre pour ses guerres contre les Romains. Rappelons que ce dernier avait de nombreux partisans à Éphèse où il fit une entrée triomphale en 88 av. J.-C. Il est donc possible que certaines familles aient conservé une certaine sympathie pour ce personnage. L'anthroponyme Pharnakès/Pharnace est quant a lui présent trois fois. Il fut porté par deux satrapes de Phrygie hellespontique ainsi que par deux souverains pontiques, respectivement le grand-père et le fils de Mithridatès VI. Enfin, il existe une occurrence du nom Cyrus qui, comme nous l'avons vu, fut rendu célèbre par le fondateur de l'empire achéménide, et une d'Orontès, qui fut porté par plusieurs satrapes et rois d'Arménie. En tout, onze à douze individus sur la vingtaine que nous avons vu ont porté des noms royaux. Il est fort possible que certains les aient adoptés précisément parce qu'il s'agissait de noms célèbres dans la littérature. Peut-être même y avait-il quelques nostalgiques de la dynastie pontique.

Reste à considérer les noms Sisinnios et Sisinès qui sont des graphies grecques différentes pour un même anthroponyme iranien. Ce nom fut porté par plusieurs personnages connus par la littérature antique dont un roi de Cappadoce, Archélaos Sisinès, client de Rome à l'époque d'Auguste. Toutefois, on peut douter que les deux Éphésiens que nous avons rencontrés aient été nommés en référence à ce personnage historique finalement assez terne. En revanche, il y a tout lieu de penser, en raison de la datation tardive de ces attestations, qu'il s'agit de chrétiens portant le nom de saint Sisinnios, un saint cavalier parthe réputé pour avoir terrassé une démone. Très honoré dans tout l'Orient où il était invoqué en parallèle avec l'archange saint Michel, son nom connut une certaine popularitée ${ }^{38}$.

\footnotetext{
${ }^{36}$ M.-F. BASLEZ, « Présence et traditions iraniennes dans les cités de l’Égée ", Revue des études anciennes 87 (1985), p.153.

${ }^{37}$ Selon que l'on considère que les noms iraniens de la liste de souscripteurs de l'Artémision concerne une ou deux familles.

38 P. PERDRIZET, Negotium perambulam in tenebris : études de démonologie grécoorientale, Paris, 1922, p. 13-19.
} 


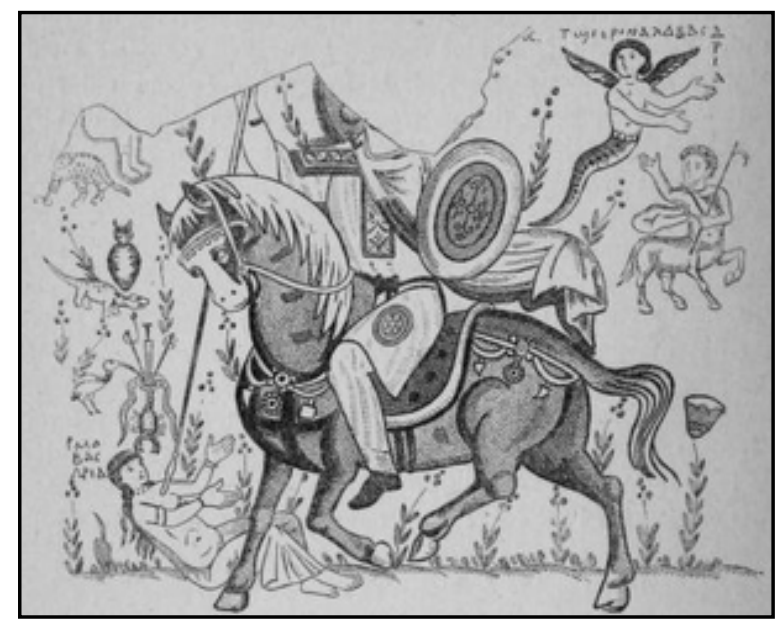

Saint Sisinnios terrassant une démone Fresque du monastère de Baouit $\left(\mathrm{VI}^{\mathrm{e}}-\mathrm{VII}^{\mathrm{e}} \text { siècle }\right)^{39}$

Entre les noms d'esclaves, la mode des noms royaux et le culte de saint Sisinnios, il semble que l'anthroponymie iranienne d'Éphèse doive fort peu à l'implantation de colons à l'époque achéménide. Cependant, un élément peut nuancer ce constat. La forte proportion de noms théophores (douze ou treize) construits à partir de Mithra (Mithridatès et Mithrès) ou d'Ahuramazdā (Mazaios) est remarquable. Le nom Mithridatès peut, comme nous l'avons dit, se référer à un souverain connu, comme Mithridatès VI. Cependant, il s'agit également d'un nom mithriaque assez répandu dans l'Asie mineure occidentale, en particulier dans les régions où la diaspora achéménide a laissé des traces, comme à Sardes ou dans la plaine hyrcanienne. Il est donc possible que, selon les familles, cet anthroponyme ait été donné pour des raisons culturelles et, notamment, religieuses plutôt que pour mettre en avant un goût particulier pour l'Histoire et la littérature classique. De même, Mithrès peut, selon les cas, avoir été un nom d'esclave ou un nom donné pour sa connotation religieuse. Il est donc tout à fait vraisemblable que ces noms mithriaques et mazdéens soient le reflet d'une origine iranienne. Au cours des siècles, ces noms auraient continué d'être donnés dans ces familles de plus en plus hellénisées par habitude sinon en souvenir de leurs lointaines origines. Quoi qu'il en soit, même en acceptant cet élément, il est flagrant que les noms iraniens de l'onomastique éphésienne sont trop difficiles à interpréter pour être d'une grande utilité pour appréhender le phénomène de diaspora impériale achéménide dans cette cité. Sur ce point donc, la «barbarisation» d'Éphèse fustigée par Plutarque semble avoir laissé bien peu de traces.

39 P. PERDRIZET, Negotium perambulam in tenebris : études de démonologie grécoorientale, Paris, 1922, fig. 6. 
